\title{
O KUDURO, PRÁTICAS E RESIGNIFICAÇÕES DA MÚSICA: CULTURA E POLÍTICA ENTRE ANGOLA, BRASIL E PORTUGAL
}

Frank Marcon*

frankmarcon@oi.com.br

RESUMO: O kuduro é um estilo de música e dança que surgiu em Angola na década de noventa e se espalhou por vários países sendo ressignificado em diferentes contextos. Neste artigo, analiso as implicações do estilo no Brasil e em Portugal, também em Angola, a partir das conotações sociais, políticas e culturais que a produção e o consumo vão adquirindo em contextos particulares de imigração e de produção midiática. As práticas e os discursos sobre o kuduro se distinguem e abrem possibilidades analíticas para pensarmos temas implicados por discursos e processos de identificação nos cenários contemporâneos globalizados, além da necessidade de reflexão sobre as novas características da música como fenômeno social na era digital.

Palavras chaves: Kuduro; Música; Identidade; Brasil; Angola; Portugal.

No cenário contemporâneo, os fluxos de produtos culturais são muito velozes e constituem um fenômeno social que precisa ser compreendido numa perspectiva do cruzamento de questões tanto locais quanto globais. Tais fluxos interferem nos modos de agir e de significar de diferentes grupos sociais, a partir das referências e das sensibilidades de aproximação que são estabelecidas pela circulação circunstancial de pessoas ou pela migração, bem como pelas formas de acesso, de contato e de solidariedades estabelecidas através das tecnologias de comunicação e informação. A música, como produto cultural, é uma expressão de grande circulação em tais contextos, se tornando uma interessante forma de comunicação entre pessoas de lugares distantes, mas também produtora de diferentes modos de uniformização de práticas e sentidos ou, pelo contrário, de reação a tais uniformizações e grandes mensagens ideológicas.

Este artigo é fruto de pesquisas que venho realizando sobre o kuduro e as múltiplas relações existentes entre este estilo de música e dança com o debate conceitual

\footnotetext{
* Professor do Departamento de Ciências Sociais, da Universidade Federal de Sergipe. Coordenador do Grupo de Estudos Culturais, Identidades e Relações Interétnicas (GERTS). Doutor em Antropologia Social pela UFSC e Pós-doutoramento em Antropologia pelo Instituto Universitário de Lisboa, Portugal
} 
sobre juventudes no Brasil, Angola e Portugal, associado à discussão sobre as dinâmicas dos processos identitários contemporâneos. Nos anos noventa ocorreu a criação e consolidação da Comunidade dos Países de Língua Portuguesa (CPLP), oficializada no ano de $1996^{\mathrm{i}}$. A CPLP foi formada congregando os países Angola, Brasil, Cabo Verde, Guiné Bissau, Moçambique, Portugal, São Tomé e Príncipe e Timor Leste. ${ }^{\text {ii }}$ Esse tipo de comunidade e de aproximação transnacional e transcontinental com alusão à "Língua" se inscreve em interesses outros de cooperação técnica, econômica e política, em meio as crescentes formações contemporâneas de blocos regionais, nos quais são realizados constantes rearranjos hegemônicos. A CPLP é uma instituição que atua no sentido de consolidar um modelo de comunidade supranacional, onde a idéia de língua portuguesa e a de história político-cultural comuns são chamadas a representarem os fatores que justificam sua coesão. Tal composição interfere política e ideologicamente nos processos de identificação locais.

O kuduro é um estilo de dança e música que surgiu em Luanda, nos anos noventa, e que chegou a Portugal logo em seguida através das relações entre os imigrantes e o seu país de origem, chegando pouco depois também ao Brasil, além de se tornar conhecido em várias outras regiões do mundo. O que torna o estilo um referencial interessante para pensarmos o contexto triangular das implicações culturais e políticas destas dinâmicas transnacionalizadas (entre Angola, Brasil e Portugal), que podem tanto estar reproduzindo velhas referencias de identidade quanto criando novas formas políticas de entender o mundo e pensar o estado nacional.

Em tal contexto reflexivo, algumas velhas problemáticas ressurgem ao lado de outras novas, implicadas pelas forças políticas, econômicas e culturais a partir da emergência de distintas modalidades de trânsitos internacionais, como, por exemplo: 1) As migrações preferenciais entre os países da CPLP e as condições formais e informais em que elas se re-arranjam; 2) As tensões com pauta étnica ou racial, na esfera dos limites da CPLP e particularmente em cada um dos seus países membros; 3) Os debates envolvendo afirmativas de identidade e diferença, em que as próprias noções de "comunidade de sentimento lusófona" são apelos ideológicos reiterados, com maior ou menor ênfase por alguns governos ou países; 4) A reinvenção discursiva da nação e de outros modelos de micro ou macro comunidades de sentimento, que reiteram diferenças; 5) As condições de controle ou descontrole sobre a produção, a circulação e o consumo da produção artística e cultural em espaços étnicos, nacionais ou transnacionais, que 
implicam e são implicados pela lógica comercial e comunitária que se estabelece com a existência da CPLP; 6) Além, entre outras, de questões envolvendo os argumentos sobre cooperação internacional e o seu contraponto, os debates sobre colonialismo, póscolonialismo e descolonização.

Diante de tais considerações iniciais, apesar das inúmeras possibilidades de recorte sobre a produção cultural que circula em tal contexto, destaco que meu objetivo nesse artigo é pensar sobre os trânsitos internacionais da música, dos discursos e das pessoas nas últimas décadas, a partir das apropriações de sentido elaboradas sobre o kuduro em contextos políticos e culturais em que este estilo se torna um signo de identidade em disputa.

\section{De estilo marginal de uma geração a símbolo nacional}

O kuduro surgiu em Angola como um estilo de dança e logo foi associado a um ritmo e um modo específico de se fazer música em programas de computadores pessoais. As músicas, inicialmente denominadas de "batidas", em Luanda, se caracterizavam pela velocidade rítmica e pela montagem improvisada. Nos primeiros anos, o kuduro foi essencialmente marcado por uma vertente influenciada fortemente pelas batidas de música techno ${ }^{\mathrm{iii}}$ norte americanas e européias. Em seguida, surgiu uma vertente mais voltada para a criação instrumental, sendo marcante a produção da música e o papel do DJ, do MC e dos dançarinos ${ }^{\text {iv }}$, envolvendo muitos adolescentes e jovens com tais atividades. Logo a seguir, o kuduro expandiu-se e aos poucos se tornou uma referência musical da nação angolana, dentro e fora do país, difundido pela imigração, por programas de televisão e pela internet através de sites de compartilhamento e difusão de músicas e vídeos.

O kuduro apareceu com características específicas de produção, circulação e consumo, marcado pelas condições do contexto social, político e econômico pelo qual Angola passava, sendo expressivamente associado à juventude de um dado momento. Esta geração pode ser caracterizada como tal por ter vivenciado, num mesmo momento etário, o fim do modelo socialista, a abertura do País para a economia liberal, as constantes mudanças e crises dos planos monetários e a progressiva institucionalização do pluripartidarismo, além de ter assistido o fim da guerra civil. É uma geração de jovens que conviveu entre si com a escassez de produtos de consumo e o desamparo 
social do Estado. Para pensar a noção de geração, considero aqui a relação entre os estudos sobre culturas juvenis e estilos de vida. Nesta orientação, os jovens de um contexto histórico e cultural podem experimentar as mesmas referências quanto aos usos de objetos, de espaços sociais, de gostos e práticas. No caso dos jovens dos musseques $^{\mathrm{v}}$ de Luanda (desde os anos noventa) tais condições podem ser resumidas pela escassez, tanto econômica quanto de condições de infra-estrutura ou de acesso ao trabalho, à escolarização, à política e ao lazer.

Durante a primeira década do século XXI, a forma de consumir músicas através dos suportes móveis se tornou uma realidade cada vez mais acessível pelos suportes digitais como os telefones celulares e o mp3. Mesmo num cenário de escassez, tais produtos se tornaram cada vez mais acessíveis em Luanda. Segundo Contador (2001), com a transformação da música para formatos digitais, os computadores e tais suportes modificaram tanto o consumo quanto a produção da música, tornando-a mais fluida. Os consumidores adquiriram certa autonomia sobre o que ouvem e sobre o que compartilham coletivamente, tornado-a ao mesmo tempo uma experiência do indivíduo e dos grupos dos quais ele participa.

Em Angola, o kuduro surgiu em tal contexto tecnológico, como um estilo desacreditado por não fazer parte do mercado da indústria fonográfica. Nasceu marginalizado, oriundo da periferia e considerado como sendo música de má qualidade, feita a partir de simples computadores e realizado por jovens sem qualificação formal ou musical. Seu surgimento também foi associado aos bairros e as tensões entre grupos rivais, como exemplifica o filme Guerra do Kuduro, realizado por Henrique Narciso, em que é ficcionalizada a relação de conflito entre jovens dos bairros de Luanda, mais especificamente a partir do exemplo da tensão entre grupos dos bairros dos municípios Sambizanga e Rangel. No filme é explorado principalmente como tais tensões estão implicadas pela cena do kuduro. De um lado "Os Lambas", e o líder do grupo, "Na Grelha", contra outro grupo, do Rangel, denominado "Os Vagabandas", com o líder "Puto Mira". A narrativa gira em torno da rivalidade e da violência entre os grupos por motivos aparentemente tolos. Uma garota é disputada entre os dois líderes, o que gera em seguida o conflito entre eles até acabar em tiros e mortes. Com a intenção de criticar tal comportamento, o realizador do filme narra no final uma mensagem moralizadora que faz um apelo para que os grupos cessem com este tipo de conflito cotidiano, pois 
suas próprias vidas podem se perder por motivos que o diretor do filme considera fúteis. $^{\text {vi }}$

No livro Intonations: a Social History of Music and Nation in Luanda, Angola, from 1945 to recent time, Marissa Moormann (2008) ressalta a existência de uma longa relação entre a música e os bairros periféricos em Luanda, desde as últimas fases do período colonial até história recente. Ela afirma que nos musseques a música é até hoje parte do cotidiano e do lazer, ao mesmo tempo em que é situada politicamente, por ser um modo de expressão intenso dos momentos sociais que as pessoas vivem na cidade. É como se a música, principalmente a dançante, fizesse parte das dinâmicas do processo de socialização destes bairros, através das festas familiares, dos encontros de rua e de outras modalidades de encontros coletivos. Para Mormann (2008, p. 140), a música dos musseques produz significados sociais intensos através do som, da dança, do espaço, e da história, tornando-se uma simbolização da soberania cultural das experiências urbanas em Luanda. Através da produção e do consumo da música as pessoas criaram e criam diariamente sensos próprios de coletividade.

Desde meados do século XX, o rádio foi um dos difusores responsáveis pela ampliação do universo de consumidores das músicas dos musseques, tanto no bairro, quanto para fora de Luanda. Comparando com a análise de Benedict Anderson sobre as comunidades imaginadas a partir da imprensa, Moormann (2008) caracteriza certa cronologia da música e diz que o rádio foi o motor de um mecanismo pelo qual também se imaginou a nação em Angola, pelo menos desde a década de 50. ${ }^{\text {vii }}$ Para Moormann (2008), após a independência ocorreu um hiato na produção musical no País (1975-90), por conta das ações do regime autoritário, da ausência de uma indústria fonográfica privada e do investimento estatal num estilo menos afeito ao modo dançante do semba ${ }^{\text {viii }}$, com maior ênfase a trova, o que tornava tal música distante dos desejos e dos modos de fazer dos musseques. Segundo Moormann (2008), durante a primeira década da independência, o semba passou a ser utilizado reiteradamente como símbolo da nação, embora a música na qual o Governo investia recursos era outra, mais discursiva e partidária. Só no final dos 80 e inicio dos 90 surgiu a kizomba, também dançante e influenciada pelo zouk, do caribe, e pelo próprio semba, tendo um impacto sobre a juventude da época. Em 1990, com o fim do MPLA-PT e a abertura econômica, os subsídios estatais para a música e outras expressões culturais deixaram de existir, sendo os artistas aconselhados a irem em busca de se manter a partir dos próprios recursos. 
No final dos anos noventa, o cenário da música era outro, o cd-rom foi substituindo as fitas k-7 como suporte e, além do rádio e da internet, também os candongueiros (táxi lotação) se tornaram meios importantes de difusão da música em Luanda, através dos sistemas de som instalado nos carros. Antes de chegar às rádios, as músicas circulavam de mão em mão em suportes de cds comprados na rua e tocados nos aparelhos sonoros dos transportes de lotação. Logo o kuduro foi se tornando muito popular. O estilo, que já nasceu implicado pela presença dos computadores no seu modo de produção, se tornou rapidamente a principal expressão musical da vida cotidiana das pessoas simples dos bairros de Luanda, principalmente dos jovens, que através da música passaram a falar do dia-a-dia, de suas intrigas, das festas que realizavam, de formas de civismo, da guerra que assombrava o País e das implicações da escassez ${ }^{\text {ix }}$ sobre o comportamento social de sua geração.

A música esteve sempre associada à dança quando se pensa no kuduro, nela é dada ênfase ao desempenho corporal, muito associado à jocosidade de movimentos de pernas, braços, nádegas, ombros e cabeça. A expressão da dança é visualmente tão significativa no kuduro, quanto o aspecto sonoro, sendo que a característica mais interessante é que neste caso a linguagem veicula num suporte que muitas vezes é o único capital que estes jovens possuem: seu próprio corpo. Com relação às habilidades musicais, o DJ se torna fundamental no processo de produção, pois ele domina uso do computador e dos programas de edição de música. A partir de microcomputadores baratos começaram surgir inúmeros jovens dedicados a esta atividade, bastava uma máquina que rodasse um programa como o fruyt loops (um dos primeiros e mais populares), alguma curiosidade e tempo livre para exercitar e fazer.

O filme Luanda, a fábrica da música, produzido em 2008, pelos diretores Inês Gonçalves e Kiluange Liberdade é um interessante registro destes modos de fazer. O argumento do documentário é basicamente sobre como é realizada a produção local da música na periferia de Luanda, a partir de um estúdio localizado no bairro Sambizanga. A narrativa do filme segue o dia a dia dos DJs Buda e Olávio. Na sua própria casa, eles mantém seu espaço de produção musical, onde produzem suas músicas e recebem os grupos que desejam gravar. Muitas vezes, eles criam apenas os beats (batidas) e os vendem para outros adicionarem os versos. DJ Buda diz que gravam diversos estilos, mas a grande maioria é kuduro. Pelos grupos que aparecem no filme, vê-se que são muito jovens. Buda usa a expressão "kuduro do gueto" para se referir ao tipo de kuduro 
gravado em sua casa. Diz que muitos grupos fazem referencias em suas músicas a outros grupos de jovens considerados seus oponentes nos bairros do Sambizanga, Rangel e Rocha Pinto.

Nas músicas também se inserem muitas expressões das linguagens ordinárias de um dado bairro, a partir da composição étnica e social migratórias de suas formações comunitárias. Tais expressões servem como códigos ou forma de comunicação dirigida entre os grupos ou dentro dos grupos, fazendo referências à polícia e a outras situações que não querem ou que desejam que sejam facilmente percebidas. Numa declaração de um dos DJs, ele diz sobre o kuduro que "essa inspiração vem mesmo de nada" e segue "acho que do barulho", o que pode ser entendido pela vontade de livre expressão e pela ideia de que fazer barulho é uma forma de dizer algo sobre si, os amigos, o cotidiano e o próprio estilo musical, de batidas rápidas e fortes, acompanhadas de palavras de ordem e do som estridente. Os apelidos dos músicos e dançarinos também dizem alegoricamente algo sobre a ideia de auto-representação como lideranças de um dado lugar, afirmando que são representantes de um valor ético ou estético que se quer ressaltar, às vezes associado à ideia de ostentação e poder, como: "Rei Helder", "Presidente Gasolina", "Pai Diesel", "Puto Prata", "SeMal”, "SeBem”, entre outros.

Foi na última década que o kuduro passou de estilo marginal da música angolana, a uma referência de símbolo nacional. Nem por isto os modos de produção e de circulação passaram a ser controlados pelo governo ou pela indústria fonográfica, embora alguns DJs, dançarinos e MCs tenham ganho espaço na mídia que se estruturou a partir do fim do controle do Estado sobre a economia e a produção cultural, com abertura de novos canais de televisão e rádio, e com a ampliação da rede de internet. Por exemplo, há bem menos de dez anos alguns programas na rádio e na televisão passaram a dar grande espaço para a música e os artistas do kuduro, como é o caso do programa "Sembre a Subir", da Televisão Pública de Angola, que é apresentado por um dos primeiros músicos a fazer o estilo nos anos noventa, além de outros programas de entretenimento e entrevistas de grande audiência como o "Hora Quente", o "Janela Aberta" e o "Tchilar", que reforçam a ideia de que o kuduro foi sendo reconhecido e construído como símbolo nacional, principalmente por ter se tornado também popular fora de Angola. Atualmente, o nome de uma música de grande repercussão no País, "Windeck", lançada no ano de 2010, se tornou também o nome de uma das primeiras novelas de produção angolana, sendo a referida música o tema de abertura. 
Em síntese, o estilo nascido de um cenário de escassez, a partir da iniciativa de uma geração emergente na era dos computadores e da internet, que deu uma nova configuração sobre o formato da produção e da circulação da música no País, continua falando do seu cotidiano e de seu contexto marginal. De qualquer modo, o kuduro tornou-se também um estilo para o qual e sobre o qual também se constrói e imagina a Angola contemporânea, como nação do pós-socialismo, do fim da guerra civil, do liberalismo econômico, de liderança regional na África e do modelo de cosmopolitismo caótico da cidade de Luanda.

\section{Kuduro: a disputa pelo sentido e os paradoxos da lusofonia}

Em Lisboa, o kuduro foi se configurando como um dos modos de expressão da juventude da periferia desde meados dos anos 90, e pelo menos do ano de 2005 para cá se estabeleceu também no mercado fonográfico, principalmente através do grupo Buraka Som Sistema, que se tornou um grande sucesso de vendas. Nos últimos dez anos, Portugal tornou-se um espaço de produção e consumo informal do kuduro, mas também de comercialização profissional da música e da dança puxadas pelo estilo.

A presença da denominada música africana (morna, koladera, funaná, kizomba, kuduro) entre os jovens portugueses negros, remete a um processo de identificação, que passa pela pertença de referência a um coletivo etnicizado, que envolve a família (CONTADOR, 2001) e os lugares de moradia. É como se a música corporizasse uma etnoreferência mimética dos significados da diáspora. Ou melhor, um imaginário que inclui num mesmo plano de percepções a migração, a exploração do trabalho, o racismo e a periferização versus a origem, o paraíso perdido e a harmonia cultural. O kuduro é uma destas presenças simbólicas produzidas a partir da linguagem e do imaginário da imigração angolana e africana em Portugal após a descolonização, mas ainda marcada pela experiência histórica do colonialismo na África. Os imigrantes são de algum modo os significantes destas ambivalências (BHABHA, 1998), do pós-colonialismo.

Analisando a relação entre o contexto de formação da CPLP, o "contexto póscolonial" e a imigração, Bela Feldman-Bianco (2002) sugere a necessidade de reflexões atentas sobre a relação entre o cenário internacional, as reconfigurações dos contextos sociais e econômicos em que elas ocorrem e as políticas de imigração. Tais implicações

Frank Marcon. O KUDURO, PRÁTICAS E RESIGNIFICAÇÕES DA MÚSICA: CULTURA E POLÍTICA 
devem ser analisadas não apenas quanto ao volume numérico, mas também sobre sua presença simbólica. Para o caso desta análise, a atenção recai sobre a presença da música e concordo com Contador (2001) sobre a ideia de que em certa medida a identidade estética está relacionada a todo um estilo de vida que os imigrantes e seus filhos levam. Sendo assim, a música associada aos africanos em Portugal é também associada aos bairros considerados socialmente frágeis e violentos, funcionando também como estereótipo de marginalização espacial de uma manifestação cultural, embora antes de tudo também marcada pelo fenótipo.

Neusa Gusmão (2004) cita exemplos de narrativas de vida de sujeitos que dizem terem chego a Portugal e se descobertos antes como "imigrantes" e depois como "africanos" (mesmo tendo referencias nacionais ou étnicas mais fortes, até então), pela persistência dos estereótipos coloniais racializados em Portugal. Entre os diacríticos definidores dos rótulos dados aos imigrantes como estrangeiros e inferiores, aparece a marca da alteridade definida pelo fenótipo e em seguida pela ideia de pobreza. Para Gusmão (2004), os imigrantes negros oriundos dos países africanos de língua portuguesa (PALOPs) ou seus filhos e netos são considerados genericamente como africanos em Portugal (2004, p. 111). Isto significa que "africano" torna-se uma categoria operacional, cotidiana e relacional no contexto português para denominar pessoas negras, ao ponto de lhes ser atribuída uma condição de estrangeiros, mesmo quando naturais de Portugal. Na prática, num contexto em que os portugueses aos poucos tomam consciência de seu pertencimento à União Européia e com ela vão construindo um laço de identificação, o contrário equivale a opor um "ser europeu" (incluso portugueses brancos) versus um "ser africano" (incluindo portugueses negros). Um princípio moral, pautado mais pela ideia de consanguinidade, de fenótipo e de cultura, e menos pela coabitação territorial, o que não integra plenamente os imigrantes e seus descendentes.

O Governo ao lado da mídia tem sido uma forte porta voz do discurso de que positivamente a língua portuguesa agrega diferentes povos dos quatro continentes, por um sentimento coletivo que se expressa pela oralidade, pela música, pela literatura e pela dramaticidade. Embora a idéia de pertencimento à Europa seja o seu ponto de referência de prestígio na relação com os outros países da CPLP, esta ideia de comunidade foi se construindo paradoxalmente com relação à noção portuguesa de pertencimento à Europa. Ou seja, os aspectos simbólicos da presença dos africanos, os 
números da imigração nas últimas décadas e as inúmeras políticas de Estado para ajustamento destas populações são informações significativas para se perceber a preocupação em regular a integração residencial, escolar, laboral e de lazer dos africanos em Portugal ${ }^{\mathrm{x}}$.

O exemplo do grupo Buraka Som Sistema, e o kuduro, podem ser interessantes para a análise desta questão e de como se processam ambivalências na ideia de lusofonia $^{x i}$. O estilo chega a Portugal através dos imigrantes angolanos e aos poucos se estabelece no gosto de toda uma geração de jovens imigrantes africanos, que se avizinham nos chamados bairros sociais. A dissertação de mestrado de Bringel (1998) é o primeiro registro que encontrei sobre o estilo em Portugal, informação que confere com alguns depoimentos de jovens "africanos" que entrevistei no ano de 2010, em Lisboa. É recorrente a afirmação de que eles dançavam e ouviam o kuduro em suas festas familiares, no espaço escolar, nas ruas e nas discotecas, até que surgiram os primeiros grupos de dançarinos, DJs, MCs e o kuduro começou também a ser produzido por eles através de microcomputadores e estúdios caseiros, numa lógica de circulação muito semelhante a que vimos no capítulo anterior sobre Luanda, embora em Portugal não apenas os angolanos, mas outros moradores dos bairros periféricos, principalmente das áreas com presença de imigrantes oriundos de países africanos, também se envolveram.

Tentando perceber o desenrolar deste processo na opinião da imprensa, realizei um levantamento de notícias no jornal Público, desde janeiro de 1995 e apesar da recorrência com relação à importância dada pelos jornais à África e especificamente Angola, em nenhum momento, até o ano de 1999, encontrei qualquer menção ao kuduro. A primeira vez que aparece a palavra é numa notícia que trata de uma escola na periferia de Lisboa (no município de Amadora) e discorre sobre os ritmos musicais que circulam entre os alunos, destacando-se estilos como o funaná, a kizomba e o kuduro. Até o ano de 2005, de modo muito ocasional e esparso aparecem algumas notícias associadas a outros temas que tangencialmente mencionam o kuduro. Só a partir do surgimento do grupo Buraka Som Sistema (BSS) e de seu sucesso repentino é que as informações sobre o kuduro aparecem com alguma frequencia e neste caso associadas ao grupo, o que se repetiu nas pesquisas que também realizei com os jornais Correio da Manhã e Diário de Noticias. O ponto alto das notícias é o sucesso internacional 
alcançado pelos BSS, primeiramente na Europa e depois na América, sendo um dos grupos musicais mais premiados internacionalmente nos últimos anos.

A atenção dada em tais jornais é basicamente sobre o sucesso do grupo, sobre sua repercussão internacional na Europa, sobre as biografias de cada membro (Kalaf, Konductor e Petty viveram em Angola) e sobre a origem do estilo musical que eles tocam. Atento a algumas das entrevistas publicadas, percebi que com o correr dos anos os membros do grupo afirmam que a sua inspiração musical é o kuduro, mas que cada vez mais utilizam o estilo para um projeto mais amplo de música eletrônica, misturando várias outras sonoridades. Enquanto isto, os jornais reiteradamente ressaltam a ideia de mistura de ritmos e criatividade dos BSS como um produto português. O fato é que eles emergem desta cena periférica da imigração africana e passam a ser considerados e reiterados pela mídia nacional como os maiores e mais atuais representantes da "música jovem" no País. O curioso é que mesmo que a mídia tenha dado tal espaço e visibilidade ao grupo e ao kuduro, durante muito tempo o impacto deste nos jornais se resumiu ao BSS. As dezenas de grupos existentes nos diferentes bairros sociais de Lisboa, desde os anos 90, não chegaram aos grandes circuitos e estão longe de qualquer reconhecimento, numa condição de invisibilidade e marginalização social na imprensa.

Enquanto os BSS são tratados como os representantes mais contemporâneos da renovação da música portuguesa (resultado do que é imaginado como contato de algum amálgama cultural lusófono e europeu), todo o restante da cena jovem dos bairros de imigração que produzem kuduro é considerada africana. Este antogonismo que inclui e afasta os imigrantes da ideia do que é "ser português" é um sintoma da percepção social hierarquizada do Estado sobre a nação e de suas contradições. A lusofonia está mais para uma ideologia que procura ajustar a imagem de grandeza como uma particularidade da nação portuguesa (pela língua e pela história colonial) e de como ela se quer representada como parte da comunidade européia, do que para uma possibilidade de pensar as diferenças e as assimetrias de poder implicadas pelo preconceito direcionado aos africanos. Aí há uma relação implicada pela memória política e cultural de centralidade metropolitana que o Estado português preserva sobre o passado colonial, por antagonismo a condição real de seu lugar periférico ocupado na geopolítica da União Européia.

O kuduro há mais de anos está presente em localidades específicas de residência de imigrantes na Área Metropolitana de Lisboa (na periferia dos municípios: Amadora, Barreiros, Odivelas, Oeiras, Sintra, entre outros), onde se misturam outras formas 
musicais e plásticas de expressões juvenis, como o rap, o hip-hop e o reggae. Ele também aparece nas chamadas discotecas africanas, onde a música é reproduzida e difundida, bem como em eventos musicais específicos que lhe dão visibilidade mais difusa e efêmera, misturado a outros ritmos como afrobeat, afrohouse e kizomba. Além disto, o kuduro é confundido com outras formas de música eletrônica, em que a produção em microcomputadores e a criação dos bits, com ou sem ênfase às letras politizadas, também dão o tom a uma cena dance music animada por DJs. Nas denominadas discotecas africanas e nas diferentes festas culturais realizadas em Lisboa, as músicas e os músicos ganham maior visibilidade e ganham reconhecimento local onde circulam.

Deste tipo de experiência surgiu o grupo Buraka Som Sistema, da música que ouviam no subúrbio somada a mistura eletrônica da cena dance e techno européia, tornaram a sua referência simbólica de periferia e de imigração africana um elemento particularmente autoral bem trabalhado na mídia. Mesmo que hoje os BSS se distingam dos outros músicos de kuduro em Lisboa e sua música circule em escalas mais amplas, com grandes audiências, virando moda em festas em Portugal e toda a Europa, as suas referências iniciais tiveram relação estreita com a realidade cotidiana de muitos outros jovens dos bairros sociais e o acesso às músicas produzidas em Angola.

Nos últimos anos, para além dos BSS, a difusão e circulação do kuduro ocorre também através dos canais de rádio (Antena 3 e Rádio África), TV (Afromusic e RTP África) e internet. Com a audiência e o consumo mais ou menos direcionados ao público de imigração africana. Este terreno está diretamente articulado com o que se torna sucesso nas discotecas (neste caso, a especificidade das discotecas é que a audiência é coletiva). Se a audiência da TV, do Rádio e da Internet são formas mais individualizadas de consumo e se realizam através das escolhas que os ouvintes fazem dos canais de comunicação, é nas escolas, nas festas comunitárias e nas discotecas que se realiza o reconhecimento coletivo sobre o que as pessoas mais ouvem e gostam. Por exemplo, no ano de 2010, alguns dos kuduros mais tocados em rádios e TVs fechadas eram de músicos que estavam em determinado momento no topo dos mais ouvidos em Angola, como: "AGregG", "Puto Prata", "Bruno M", "Game Valla”, "Puto Lilas", "Puto Lilás", "Dog Murras", “Os Lambas", "DJ Sottão" e "Cabo Snoop".

A facilidade de acesso a tais referências musicais, contribuiu para perpetuar um vinculo cultural e de sentimento de identificação. Em Portugal, as músicas africanas de 
maior acesso vêm de Angola e Cabo-Verde, com predomínio das primeiras quando se trata da música produzida e destinada as gerações mais jovens. Isto contribui para que a socialização do kuduro seja amplamente difundida entre os imigrantes e o estilo seja resignificado pelos africanos em Portugal, como elemento importante de identificação cultural.

Por outro lado, um sintoma de como a lusofonia é difundida e partilhada por governos, imprensa e empresas privadas também pode ser observado pela forma com que as grandes lojas e redes de vendas de música expõem e classificam os estilos em suas prateleiras. Na FNAC, a divisão das secções de música não traz o "kuduro" como estilo autônomo (como o rock, o fado ou o MPB) e a venda dos discos dos BSS estão na sessão de "música eletrônica", de música "dance music" ou de "música portuguesa". Já os poucos discos de kuduro de artistas angolanos são classificados na secção "África" ou na secção de músicas dos "PALOPs". Não há discos de kuduro de qualquer outro grupo de jovens imigrantes, muito menos qualquer um na classificação "música portuguesa"xii, esta é uma prerrogativa exclusiva do BSS.

Assim sendo e inspirado pela dissertação mestrado de Olivier Guiot (2009), ressalto dois modos de expressão do kuduro em Portugal. Considero ambos como expressão demográfica e suburbana, embora o estilo do Buraka Som Sistema possa ser classificado como expressão hegemônica pela sua exposição midiática de audiência comercial, enquanto que outros grupos desconhecidos da mídia mantêm uma condição de expressão periférica. Os BSS são vistos e se assumem como uma expressão comercial de subcultura (por exemplo, por utilizarem o nome do bairro Buraca, como um significante de sua origem da periferia, quando este bairro de imigrantes africanos é um dos mais emblemáticos desta presença associada à marginalidade), enquanto os outros grupos são pouco ou nada midiatizados, como é o caso dos grupos: BF, Gala Squad, Ki kuiam, K55, Mil Mambos, Massaba, Nova Geração, Ngapa, Staff da KebraDa e Staff Estraga. Estes se exprimem por uma identificação ambígua com o modelo BSS, de um lado porque a expressão deste legitima o lugar do kuduro como música periférica num circuito de aceitação, positivação e reconhecimento social, mas de outro se distancia das peculiaridades do modo pelo qual o kuduro é produzido e consumido nos bairros sociais onde residem.

Tal contexto demonstra o quanto disputas pelos signos culturais podem produzir distintas ordens de identificação com o estilo. No livro Dimensões culturais da globalização: a modernidade sem peias, Arjun Appadurai (1996) faz uma interessante 
constatação de que é a partir do final dos anos 80 que a diáspora mundial passou a ser afetada pelas transformações eletrônicas globais, substantivamente pelo viés da comunicação. Ele diz que: "o fluxo global de imagens, notícias e opinião fornece parte da literacia cultural e política militante que as pessoas da diáspora trazem para seus bairros espaciais" (p. 261). Eu penso que para o caso da imigração africana e da geração que ouve e faz o kuduro em Portugal, por mais que os BSS representem alguma ambigüidade, o estilo agrega um sentido de identificação local, presente nos bairros e nas conexões entre eles, marcando uma presença física e simbólica que desarrumam as ideologias hegemônicas que as periferizam, invisibilizam homogeneízam ou menosprezam, como é o caso da lusofonia.

\section{Música africana, identificação ou exotização}

No Brasil, o kuduro chegou a partir dos trânsitos de angolanos refugiados, estudantes, comerciantes e turistas, principalmente (mas não somente), através de cidades como Rio de Janeiro, Salvador e São Paulo. A presença do estilo não está necessariamente concentrada em locais com grande público de consumo ou difusão (como vimos nos exemplos anteriores), embora seus sentidos sejam também disputados com alguma especificidade num contexto mais amplo que o das cidades. Destaco três contextos distintos: a) o das comunidades de imigrantes angolanos em diferentes cidades do Brasil, b) os pequenos grupos de estudantes africanos espalhados pelas universidades onde há presença de angolanos e c) alguns cenários midiáticos que recorrem ao exotismo e ao apelo a ideia do kuduro como referência à música negra como sinônima de música africana ou angolana.

Em 2009, a jornalista Natália Viana disse ter feito um levantamento junto à Embaixada de Angola e descoberto que a maioria da população angolana que se fixou no País está no Rio de Janeiro, principalmente na Rua do Riachuelo, no centro, e no Complexo da Maré. Disse que ali vivem "muitos imigrantes que vieram durante a guerra civil e formam a maior população de refugiados no país, cerca de 1.700 pessoas"xiii. Além desta presença de formas de imigração mais nucleada, que existe também em algumas outras cidades do Brasil, talvez em menor número, há também um número significativo de estudantes universitários espalhados pelo País, por conta das 
bolsas de estudos oferecidas pelo governo brasileiro para graduação e pós-graduação de estrangeiros, preenchidas em boa parte por alunos oriundos de países africanos. Neste último caso, a situação é particularmente distinta, porque é uma imigração individual e a princípio temporária, que acaba por reunir os africanos oriundos de diferentes países nas residências estudantis das universidades.

O kuduro está presente em ambos os contextos mencionados. No âmbito dos estudantes universitários, os angolanos o introduziram em meio a outras músicas originárias de Cabo Verde, Guiné Bissau e Moçambique, tornando-o um estilo que passou a ser caracterizado como um dos ritmos de música mais presentes nas denominadas festas africanas realizadas por tais estudantes. Já no caso das comunidades de imigrantes o estilo aparece nas residências e nas festas organizadas pelos angolanos. Em entrevista realizada por Viana (2009), um destes imigrantes lhe disse que se tornou DJ no Rio de Janeiro e conta-lhe que como o kuduro "já estava famoso em Angola, foi natural tocá-lo nas pistas aqui", dizendo que um dia lhe chamaram para tocar numa festa de imigrantes angolanos e que logo a música alegrou o pessoal e o dono do lugar acabou the chamando para ficar trabalhando no local. Em outras cidades do Brasil, em que há presença angolana, o estilo também aparece. $O$ fato de esta imigração ser recente, boa parte nos últimos 20 anos, fez com que muitos deles já conhecessem o kuduro, enquanto outros passaram a conhecê-lo pela dinâmica das relações de contato com os familiares e amigos em Angola e pelo acesso à internet, por onde buscam o contato com informações e o que se faz em termos de música em seu país de origem. Pelo menos durante a última década, nas festas em casas de amigos e parentes e nos encontros em discotecas, os angolanos e os estudantes africanos oriundos dos PALOPs difundiram o estilo entre si de forma pontual e pulverizada, em diferentes cidades do Brasil. O resultado desta presença é que tanto os sentimentos de identidade nacional angolana, no caso das comunidades, são exaltados como referência simbólica através da música e do kuduro, quanto à construção de um sentimento de africanidade entre os estudantes oriundos dos PALOPs, o que se opõe a ideia de brasilidade, mesmo afrobrasileira.

Numa outra linha, num cenário mais midiático, que compõe com os discursos hegemônicos que passam a predominar sobre o estilo, um dos primeiros registros televisivos do kuduro ocorreu durante o ano de 2008, quando a TV Record produziu num de seus programas (Hoje em Dia), um quadro em que as pessoas se inscreviam 
num concurso para dançar o "kuduro". O quadro surgiu depois de uma reportagem sobre Angola reproduzida para o público desta TV no Brasil. Houve uma grande participação de pessoas no concurso, mesmo que muitos declarassem ter contato pela primeira vez com aquele tipo de música e dança. Durante as edições, algumas pessoas narravam como conheceram o kuduro, enquanto os apresentadores do programa descreviam o estranhamento com relação ao estilo e afirmavam estarem admirados com esta relação de proximidade entre Brasil e Angola. É importante considerar que a Rede Record têm uma sucursal em Luanda, atua já há algum tempo naquele País e lá também produz programas locais. Depois das primeiras aparições no programa Hoje em Dia $^{\text {xiv }}$, o estilo teve outras inserções em diferentes programas da Record, com diferentes pautas, sendo sempre muito enfática a referência ao exotismo representado pelo nome do estilo, pelo tipo de música e principalmente pelo modo de dançar.

Em outro contexto midiático, o artista Dog Murras, nome consagrado do kuduro em Angola, se apresentou no carnaval baiano, o que se dá há pelo menos cinco anos seguidos. A participação de Dog Murras ocorre nos trios elétricos em Salvador e é realizada através de parcerias com grupos locais. Em suas aparições há sempre a presença de símbolos nacionais angolanos, como as cores da bandeira e o brasão nacional com a engrenagem e a foice. Dog Murras traz outros músicos e dançarinos em suas apresentações e tem se tornado uma referência de parceria com músicos brasileiros que procuram expressar aspectos de uma ideia de fraternidade negra entre Bahia e Angola ou Brasil e África, como enfatiza o artista em várias entrevistas nos bastidores de seus shows e no clipe de sua música "Alegria de Negro", em que fala de um sentimento de identificação coletiva pelo "ser negro": "Preto, negro, mulato ou moreno, alicerce do mundo moderno, eu sou o mordomo, eu sou o lixeiro, eu sou o próprio concreto, pise, abuse, pise, despreze, eu sou a natureza, respeite!!! (...) África Mãe não chore (...) ${ }^{\natural x}$. Tal retórica se aproxima das referências dos movimentos sociais e da teoria social que ressaltam os laços da África com a diáspora, como elementos da identidade negra no Brasil.

São dois aspectos distintos desta veiculação do kuduro como espetáculo no Brasil. O primeiro como signo de vínculos relacionados à ideia de fraternidade histórica associada à cultura e a população negra no País (exemplo do Dog Murras) e o segundo como elemento exótico de impacto midiático de um estilo de música que tende a salientar movimentos sensuais do corpo, além do duplo sentido que o nome do estilo Frank Marcon. O KUDURO, PRÁTICAS E RESIGNIFICAÇÕES DA MÚSICA: CULTURA E POLÍTICA 
oferece (exemplo do concurso de dança). Este último foi bastante celebrado a partir da música "Dançar Kuduro", do artista Latino, que fez enorme sucesso na internet e nas mídias convencionais, em 2011. Ressaltando as características acima, mesmo que a música do Latino seja algo muito diferente do que se faz em Angola, ele utilizou o nome "kuduro" para agregar à ideia de ritmo um sentido de sensualidade. Depois disto, também a TV Globo passou a noticiar a descoberta do estilo e o mesmo começou a aparecer em diferentes espaços de sua programação, em geral ressaltando os dois aspectos já apontados acima, o exotismo ou a afinidade com um sentido genérico de cultura negra, como no caso da última aparição do kuduro no programa Esquenta, em 10 de novembro de 2013.

Além destas implicações sobre uma simbologia das identidades, outra questão importante nos circuitos das relações de poder é o contraponto na inversão do consumo de produtos culturais entre os dois lados do Atlântico, já que Angola passou as últimas décadas como um importante consumidor de literatura, música e novelas brasileiras, além de um grande mercado receptor de bens materiais. Foi também através do kuduro, que a mídia televisiva do Brasil começou a olhar e conhecer o País e as particularidades da sua cultura urbana contemporânea, para além do exotismo sobre o tradicionalismo, embora às vezes reeditando estas referências quando associadas à idealização de que o kuduro está para as raízes da música africana, assim como para os estilos de música considerados afro-brasileiros, ressaltando-se os elementos da presença dos sons dos tambores e das habilidades dos movimentos corporais com a dança, principalmente de quadris e pernas.

\section{Considerações Finais}

Com esta reflexão sobre a relação entre o kuduro e as novas formas de comunicação, produção, circulação e consumo de música busquei pensar sobre algumas formas de relações de poder e processos identitários a partir de situações que ultrapassam o cenário das fronteiras nacionais, embora consciente de que este não é o único estilo que mereceria tal investimento. Mais especificamente, estou falando de tantas outras formas de música que nascem caracterizadas por um novo contexto tecnológico de produção e logístico de reprodução, marcadas pela circulação nuclear e centrípeta (que irradia de um grupo de amigos para uma comunidade e dali para os seus 
grupos de amigos que vivem distante). Isto se dá através dos suportes de arquivo virtual de música, chegando a vários outros bairros, cidades e países, não obedecendo às fronteiras geográficas, linguísticas ou políticas (através de computadores, mp3, telemóveis), tendo ainda outra característica que é a efemeridade, pois mesmo quando tocam muito, fazendo grande sucesso, em seguida desaparecem por não estarem agregadas a um suporte físico.

Como vimos no início deste artigo, a digitalização da música facilitou sua circulação através de suportes móveis e da internet, ocorrendo uma transformação na produção, distribuição e audiência que significou sua desmaterialização. Isto reconfigurou o mercado, a produção, a difusão e as formas de consumo musical e no caso do kuduro tornou-o um estilo de ampla repercussão e de múltiplas implicações e significados. A produção se tornou cada vez mais facilitada e o consumo cada vez mais público e gratuito, sendo algo semelhante ao que ocorreu também com alguns estilos que já nasceram na era deste formato e assim se desenvolveram, como é o caso do funk, do brega e do reggae eletrônicos, cada qual com suas particularidades. Em todos os casos, estes estilos têm suas facetas como fenômeno musical de amplo alcance, como também condições particularizadas de socialização.

Nas últimas décadas, os cenários nacionais estiveram implicados pelo debate pós-colonial e pela globalização contemporânea, que nos estimulam analisar novas modalidades de expressão de identidades e de diferenciação que apesar de fundados em alguma ideia de "localismo" estão diante de configurações sociais atravessadas por condicionantes de desterritorialização (HALL, 2003). O kuduro pode sugerir algumas reflexões neste sentido, principalmente sobre a fragilidade das explicações primordialistas e localistas sobre a identidade e a cultura. O reconhecimento das análises contemporâneas de que os processos de identificação e diferenciação passam por um primado discursivo e inventivo, não impede considerarmos que eles existam para aqueles que os utilizam (ALMEIDA, 2000, p. 238) e que devamos estar atentos para as suas lógicas e contradições.

No tempo presente, coexistem relações entre comunidades (micro)espaciais (os bairros) e comunidades virtuais de sentimento que podem ou não estar conectadas. De qualquer modo a localidade é um fato social intrinsecamente frágil para pensarmos a contemporaneidade (APPADURAI, 1996). Isto significa que as formas de atuação e significação são múltiplas e desenraizadas, necessitando análises que façam o exercício 
de acompanhar tais movimentos. Assim como a música circula pela internet, a informação e a opinião também fluem a partir de relações entre pessoas e grupos que trocam vínculos afetivos em muitas áreas da vida. Tais pessoas e grupos são capazes de mobilizar ideias, opiniões, capitais e laços sociais que produzem modos de ser, estar e sobreviver em contextos aparentemente hostis, assim como possibilitam novas formas de convívio.

Como vimos em diferentes cenários, o kuduro é um signo ativado por distintas formas de manifestações espontâneas, como no caso das experiências em Luanda, em Lisboa ou no Rio de Janeiro, ou mesmo por projetos políticos mais sólidos, como no caso de uma identificação com a lusofonia, com a nação angolana ou com a ideia de africanidade. Tais entendimentos estão em tensão por sentidos de solidariedade e modos de pensar específicos, revelando os paradoxos e as diferentes facetas dos processos de relações de poder implicados pelo simbolismo das identidades.

\section{THE KUdURO, MUSIC PRACTICIES AND RESIGNIFICATIONS: POLITICAL AND CULTURE BetWeen ANGola, BRAZIL AND PORTUGAL.}

ABSTRACT: The kuduro is a style of music and dance that emerged in Angola in early 1990s and spread to several countries being meaning in different contexts. In this article, I analyse the implications of the style in Brazil and in Portugal, also in Angola, from the social, political and cultural connotations that production and consumption are acquiring in particular contexts immigration and media production. The practices and discourses on the kuduro are distinguished and open possibilities for analytical thinking involved themes for speeches and identification processes in the contemporary globalized scenarios, in addition to the need to reflect on the new features of music as a social phenomenon in the digital age.

KEYWORDS: Kuduro - Music - Identity - Brasil - Angola - Portugal

\section{NOTAS}

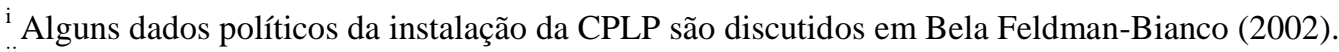

${ }^{\text {ii }}$ Para informações sobre a história da CPLP, países membros, regimentos, objetivos, reuniões, discursos oficiais dos presidentes, acessar o site www.cplp.org/

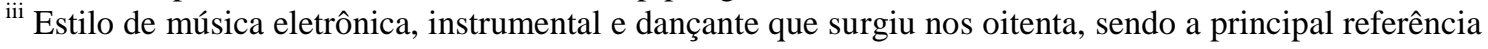
musical das festas denominadas de raves.

${ }^{\text {iv }}$ Disk Jockey, Mestre de Cerimônias e dançarinos são as três atividades dos kuduristas, como no hiphop.

${ }^{v}$ Musseque era a denominação que se dava no período colonial às regiões da cidade sem infra-estrutura urbana, eram bairros com casas de lata nos quais não chegava o asfalto e outras benfeitorias. Ainda hoje, a palavra musseque carrega a conotação de bairros com infra-estrutura parca.
} 
${ }^{\text {vi }}$ O filme saiu em formato digital, disponível no youtube, em: http://www.youtube.com/watch?v=nyAlUeRbbw Acesso 09/11/2013.

vii Para um estudo sobre Angola imaginada pela literatura, ver Marcon (2010).

viii $\mathrm{O}$ semba surgiu nos anos 50 e é até hoje um dos estilos musicais mais exaltados como símbolo de música nacional em Angola, ver Moormann (2008).

${ }^{\text {ix }}$ Sobre esta relação entre o cenário de escassez em Luanda e o surgimento do kuduro, ver: Marcon e Tomás (2012).

${ }^{\mathrm{x}}$ Há vários estudos que abordaram os impactos sociais de tal presença no Portugal, ver, por exemplo Machado \& Azevedo (2008). É importante ressaltar que ressalvando o período de fins de 90, quando a imigração ucraniana teve um forte impacto nos índices gerais da imigração em Portugal (após 2004 ela passa por refluxo e muitos retornam), os PALOPs e o Brasil juntos sempre foram os países com maiores número de imigrantes no país desde 1970, destacando-se ainda a característica cada vez mais crescente da imigração brasileira na última década. Preocupados com a regulação dos fluxos de imigrantes, principalmente sobre o impacto do emprego x mão de obra (lucros maiores com mão de obra de segunda), as medidas políticas se alteram, mas segue-se cumprindo a diretriz ideológica da recepção de imigrantes oriundos de países da CPLP.

${ }^{x i}$ A noção de lusofonia é em grande medida associada à ideia de comunidade de falantes da língua portuguesa, o que a torna um argumento poderoso na justificação da constituição da CPLP. Para uma reflexão crítica ver o livro de Alfredo Margarido (2000), A lusofonia e os lusófonos: novos mitos portugueses.

xii São dados de visitas que realizei no ano de 2010, a algumas lojas da FNAC e da Worten. Nesta última os BSS estavam classificados como "Música Portuguesa". Em algumas lojas também se encontra um outro tipo de secção: "hip-hop português".

xiii Reportagem da jornalista Natália Viana publicada em 10/10/2009, publicada no site Opera Mundi. Ver:

http://operamundi.uol.com.br/conteudo/reportagens/1516/imigrantes+trazem+ritmo+kuduro+angolano+a o+brasil.shtml Acesso em 15/11/2013.

xiv Ver, por exemplo, a final do concurso em: http://www.youtube.com/watch?v=rAX0xa3Wleo Acesso em 15/11/2013, além de outros vídeos da mesma rede de TV postados no site do youtube.

${ }^{\mathrm{xv}}$ Ver: http://www.youtube.com/watch?v=p9paJD0s9Lw, acesso em 15/11/2013.

\section{BIBLIOGRAFIA DE REFERÊNCIA}

ALMEIDA, Miguel Vale de. Um Mar da cor da terra: raça, cultura e política da identidade. Oeiras: Celta, 2000.

APPADURAI, Arjun. Dimensões Culturais da Globalização: a modernidade sem peias. Lisboa, 1996.

BARTH, Fredrik. Grupos étnicos e suas fronteiras. In: POUTIGNAT, Philippe, STREIFF-FENART, Jocelyne. Teorias da Etnicidade. São Paulo: ed. UNESP, 1998.

BENNET, A. e KAHN-HARRIS, K. After Subculture: critical studies in contemporary youth culture. Editado por Andy Bennet e Keith Kahn-Harris, 2004.

BHABHA, Homi. O local da cultura. Belo Horizonte: Ed UFMG, 1998.

CANCLINI, N. G. Consumidores e Cidadãos: conflitos multiculturais da globalização. $4^{\text {a }}$ Ed. Rio de Janeiro: Editora UFRJ, 1999.

CERTEAU, Michel de. A invenção do cotidiano. Petrópolis: Vozes, 1994.

CLIFFORD, James. A Experiência etnográfica: antropologia e literatura no século XX.

Rio de Janeiro: UFRJ, 1998.

CONTADOR, António Concorda. Cultura juvenil negra em Portugal. Oeiras. Celta

Editora, 2001.

FELDMAN-BIANCO, Bela. Entre a fortaleza da Europa e os laços afetivos da irmandade luso-brasileira: um drama familiar em um só ato. In: BASTOS, Cristiana, ALMEIDA, Miguel V. de e FELDMAN-BIANCO, Bela. Trânsitos coloniais: diálogos críticos luso-brasileiros. Lisboa: ICS, 2002.

Frank Marcon. O KUDURO, PRÁTICAS E RESIGNIFICAÇÕES DA MÚSICA: CULTURA E POLÍTICA 
GILROY, Paul. O atlântico negro. São Paulo: Ed. 34: Rio de Janeiro, 2001. GUSMÃO, Neusa Maria Mendes de. Os filhos da África em Portugal: Antropologia, multiculturalidade e educação. Lisboa: Imprensa de Ciências Sociais, 2004.

HALL, Stuart. Da diáspora. Identidades e mediações culturais. Belo Horizonte: UFMG, 2003.

MACHADO, F. L. \& AZEVEDO, J. A investigação sobre imigração e etnicidade em Portugal: tend encias, vazios e propostas. Revista Migrações, 4, 2008, pp. 7-31

MARCON, Frank. Diálogos transatlânticos: identidade e nação entre Brasil e Angola. Letras Contemporâneas: Florianópolis, 2005.

MARCON, Frank. Identidade e estilo em Lisboa: Kuduro, juventude e imigração africana. Cadernos de Estudos Africanos, 24, Lisboa, 2012, pp. 95-116.

MARCON, Frank. Kuduro, juventude e estilo de vida: estética da diferença e cenário de escassez. Revista Tomo, 21, São Cristóvão (SE), 2012, pp. 137-167.

MARGARIDO, Alfredo. A lusofonia e os lusófonos: novos mitos portugueses. Lisboa: Universitárias Lusófonas, 2000.

MOORMANN, Marissa. Intonations: a Social History of Music and Nation in Luanda, Angola, from 1945 to recent times. Ohio University Press, 2008.

OLIVEIRA, Roberto Cardoso de. O trabalho do antropólogo: olhar, ouvir escrever. In: O trabalho do antropólogo. 2a . Ed. São Paulo: UNESP, 2000.

THOMPSON, E.P. A Formação da Classe Operária Inglesa. São Paulo: Paz e Terra, 1988. 